\title{
CITRA TUBUH PEREMPUAN PADA KARYA LUKISAN AUDREY KAWASAKI
}

\author{
Citra Kemala Putri \\ Fakultas Komunikasi dan Desain Universitas Informatika dan Bisnis Indonesia \\ citrakemala@unibi.ac.id
}

\begin{abstract}
Abstrak
Audrey Kawasaki merupakan seniman perempuan Jepang-Amerika yang banyak mengangkat objek tubuh perempuan ke dalam karyanya. Sekilas, tubuh-tubuh perempuan yang digambarkan oleh Kawasaki terkesan erotis. Penelitian ini menggunakan metode kualitatif dan menggunakan teori Bahasa Rupa serta Studi Budaya untuk melihat sisi lain dari tubuh perempuan yang dilukiskan oleh Audrey Kawasaki. Hasil akhir dari penelitian ini mengungkapkan bahwa Audrey Kawasaki berusaha menjabarkan nilai identitas, gender dan seksualitas perempuan melalui gaya visualnya yang feminin
\end{abstract}

Kata kunci: lukisan, tubuh, perempuan.

Abstract

Audrey Kawasaki is a Japanese-American female artist who has launched female objects into her artworks. At first glance, the female bodies described by Kawasaki seem erotic. This study uses qualitative methods and uses the theory of Visual Language and Cultural Studies to see the other side of a female's body described by Audrey Kawasaki. The final results of this study reveal that Audrey Kawasaki is trying to describe the values of female identity, gender and sexuality through her feminine visual style

Keywords: painting, body, female.

\section{PENDAHULUAN}

Dalam perkembangan sejarah seni rupa dari masa ke masa, tubuh menjadi salah satu objek yang sering hadir dengan citraan beragam. Baik tubuh laki-laki maupun perempuan digambarkan dengan berbagai gaya visual yang dituangkan dalam bentuk dua dimensi dan tiga dimensi. Beberapa contoh citraan tubuh perempuan yang terlihat kontras berbeda antara satu dan lainnya misalnya terlihat pada karya patung Venus dari Willendorf yang berasal dari masa prasejarah Eropa dan lukisan Venus karya Sandro Botticelli.

Patung Venus dari Willendorf rasanya menjadi patung yang memiiki citra kontradiktif dengan citra kecantikan zaman sekarang. Venus yang lazim dikenal sebagai simbol cinta dan kecantikan pada karya ini dirupakan dalam bentuk patung yang gemuk, dengan menonjolkan bagian dada dan pinggul yang dilebih-lebihkan sehingga tampak tidak proporsional. Wajah pada bagian patung ini dihilangkan. Bila melihat kembali latar belakang penciptaan karya ini, bentuk seperti ini merupakan representasi masyarakat saat itu akan kesuburan dan kehidupan yang didambakan. Berbeda dengan lukisan Venus karya Sandro Botticelli, pada lukisan ini, citra kecantikan pada perempuan mendekati citra cantik pada zaman sekarang. Citra cantik ditonjolkan pada ciri fisik perempuan yang dianggap Venus tersebut. Anatomi tubuh Venus pada lukisan ini dilukiskan lebih natural dan proporsional.

Dua karya di atas merupakan bentuk citra perempuan yang diungkapkan melalui karya visual, meskipun demikian citra perempuan dapat pula diungkapkan secara verbal melalui karya sastra. Baik citra perempuan yang diekspresikan baik melalui bahasa verbal maupun lewat bahasa visual, keduanya 
merupakan perwujudan dari konsep perempuan yang dilihat dari latar belakang suatu bangsa, kelompok etnis atau bahkan perorangan. Ini yang menyebabkan adanya keragaman pada bentuk citra perempuan ( Nadhiputro, 2012: 51). Contoh lainnya, dalam tradisi Jawa, perempuan disimbolkan sebagai sumber keberuntungan atau kesuburan (Dewi Sri). Selain itu, perempuan juga disimbolkan sebagai bumi yang mengayoni (Dewi Pertiwi). Namun, selain dicitrakan positif, dalam perspektif gender, sebaliknya, perempuan sering juga dicitrakan secara negatif. Misalnya dipandang sebagai sosok inferior di bawah subordinasi laki-laki. Perempuan, dalam masyarakat patriarkhi ditempatkan lebih rendah di bawah laki-laki. Atribut-atribut perempuan seperti lemah lembut, pasif, patuh, ketergantungan dan sifat-sifat feminitas yang lain bila dilihat dari perspektif gender bukanlah kodrat akan tetapi konstruksi sosial yang dibuat oleh kaum laki-laki (Nadhiputro, 2012: 50).

Audrey Kawasaki mulai mempublikasikan karyanya pada tahun 2005. Kawasaki menggunakan media panel kayu, cat minyak dan graphite dalam melukis karyanya. Hampir semua karya Audrey menggunakan objek perempuan dengan berbagai eksplorasi pada gestur, ekspresi, pakaian dan elemen dekoratif. Hanya segelintir karyanya yang menampilkan sosok laki-laki. Dalam penelitian ini peneliti berusaha menjabarkan berbagai citraan tubuh perempuan yang tampak pada beberapa lukisan Kawasaki jika dilihat dari ranah Bahasa Rupa dan Studi Kebudayaan.

\section{KAJIAN PUSTAKA}

Sebuah lukisan atau gambar merupakan karya yang kasat mata. Oleh karena itu, bahasa rupa gambar umumnya dapat digunakan untuk menyebut segala hal yang berhubungan dengan 'rupa' dari suatu gambar. Sementara yang dimaksud gambar adalah sesuatu yang mengacu pada bentuk visual di bidang yang 2 dimensional, contohnya sketsa, lukisan, foto, karya grafis, relief, layar lebar, layar kaca (tv), layar monitor (komputer), dsb (Tabrani, 2012: 132).

Bahasa rupa adalah ilmu yang dapat digunakan untuk membaca gambar gua prasejarah, primitif, tradisi juga gambar anak meskipun gambar tersebut tersaji tanpa teks. Tabrani membagi bahasa bahasa rupa menjadi dua. Pertama, NPM (Naturalis-PerspektifMomenopname) yaitu bahasa modern dari barat dan yang kedua adalah RWD (Ruang-WaktuDatar) (Tabrani, 2012: 3).

Beberapa ciri sistem bahasa rupa RWD antara lain: belum mengenal 'ukuran pengambilan', setiap objek pada gambar umumnya digambar seluruh badan dari kepala hingga kaki. Intinya, RWD lebih bercerita dengan gestur, sementara NPM menekankan pada ekspresi wajah. Pada RWD, suatu objek digambar dengan menonjolkan karakteristik khas yang mudah dikenali. Bila suatu kejadian penting diceritakan, maka digunakan cara 'sinar $\mathrm{x}$ ' atau tembus pandang, adanya cara menggambar 'ruang angkasa', cirinya objek digambarkan terbalik-balik, maksudnya ada suatu yang berkeliling, tiap objek dapat digeser seluruhnya atau sebagian hingga semua bagian nampak dan bisa diceritakan satu sama lain (Tabrani, 2012: 137).

Dalam kebudayaan konsumtif, tubuh diartikan sebagai subjek komoditas yang terus berkembang dan berubah-ubah. Kathy Davis mencatat bahwa budaya komoditi juga telah membuat komoditi tubuh kita sebagai sesuatu yang membingungkan. Segala ekspresi-ekspresi perilaku nonverbal seperti sikap, tatapan mata, sentuhan, kedipan, dan lainnya merupakan ekspresi tubuh yang dapat berbicara tanpa suara dan melengkapi apa yang diungkapkan oleh pakaian dan perhiasan seseorang (Rogers, 2009: 174). Tubuh sebagai produk ragawi juga dapat dijadikan sebagai pembeda gender. Gender pada koridor ini bukan hanya digunakan sebagai pembeda jenis kelamin secara biologis dan fisiologis saja, melainkan gender, maskulinitas dan femininitas sebagai fenomena kultural. Penelitian ini menggunakan teori Bahasa Rupa 
serta Studi Budaya untuk melihat sisi lain dari tubuh perempuan yang dilukiskan oleh Audrey Kawasaki.

\section{METODE PENELITIAN}

Penelitian dititikberatkan pada beberapa karya lukisan Audrey Kawasaki yang mengambil objek perempuan serta diambil secara acak dari beberapa periode waktu pengerjaan. Penelitian dilakukan dengan menggunakan pendekatan studi kebudayaan dan bahasa rupa, baik bahasa rupa modern (NPM) dan bahasa rupa tradisi (RWD). Metode yang digunakan dalam penelitian ini adalah metode kualitatif. Data yang disajikan dalam penelitian ini merupakan data yang diperoleh dari berbagai macam sumber literatur baik cetak maupun elektronik.

\section{PEMBAHASAN}

\subsection{Introduksi Audrey Kawasaki}

Audrey Kawasaki merupakan seniman Jepang-Amerika, lahir dan dibesarkan di Los Angeles, yang sekarang menjadi tempat dia tinggal dan bekerja. Komik manga Jepang adalah hal awal yang menginspirasi Kawasaki untuk menggambar sejak usia dini. Kawasaki kemudian mengambil kelas seni di Mission Renaissance di akhir masa remajanya untuk mempelajari dasar menggambar dan melukis. Setelah lulus SMA, Kawasaki berkuliah di Pratt Institute di New York, tetapi dia memutuskan untuk meninggalkan kursi kuliah setelah 2 tahun tanpa mendapatkan gelar sarjana. Namun setelah itu Kawasaki mulai berkarya secara professional dan aktif dalam berpameran di berbagai galeri seni baik di Amerika maupun di negara lainnya sejak tahun 2005.

Karya Kawasaki mengangkat tema kontras mengenai kepolosan dan erotisme, yang di dalamnya terdapat intrik misterius sensualitas wanita. Objeknya digambarkan secara tajam dan presisi pada panel kayu, sehingga aksen naturalnya menambahkan kehangatan pada karyanya. Selain komik manga Jepang,
Kawasaki juga dipengaruhi oleh tradisi timur dan barat seperti Art Nouveau yang terlihat di beberapa karyanya. Secara umum Kawasaki melukis perempuan yang terlihat gemar menggoda dengan garis yang halus, provokatif, dan mayoritas dilukiskan dengan tatapan mata langsung ke arah depan. Gestur para perempuan yang anggun tapi kadang terlihat seperti hantu dengan tepat menyampaikan ekspresi misterius yang melankolis.

Tubuh di dalam karya seni rupa dipandang sebagai suatu sistem simbol. Pengalaman fisik yang dialami tubuh selalu berubah dan dimodifikasi oleh kategori-kategori social yang sudah diketahui, salah satunya melalui pandangan tertentu masyarakat ( Lie, 2015: 26). Dalam perkembangan karya seni rupa dan desain, tubuh telah menjelma menjadi lingkungan visual di mana pun kita berada. Berbagai citraan yang dirupakan melalui visual tubuh digunakan pada billboard iklan, tayangan di televisi, aneka video, majalah, koran dan tabloid. Hal ini seperti menegaskan bahwa tubuh menjadi satu-satunya bahasa komunikasi yang paling mudah dimengerti. Di luar ranah seni rupa dan desain, tubuhpun sering menjadi bentuk representasi berbagai kepentingan dan persoalan ekonomi, sosial, dan politik. Tubuh menjadi suatu rupa yang di padanya dapat dititipkan representasi berbagai realitas yang ada dalam masyarakat yang disajikan kembali lewat karya seni rupa. Tubuh dirupakan dalam beragam bentuk, medium dan gaya yang berbeda-beda sesuai dengan gagasan pemikiran dan latar belakang perupanya (Lie, 2015: 25).

Audrey Kawasaki merupakan salah satu seniman perempuan yang selalu mengangkat objek tubuh manusia di semua karyanya. Penelitian ini akan membagi pembahasan karya Kawasaki ke dalam 3 tema, antara lain tubuh dan ekspresi perempuan pada karya Kawasaki, tubuh dan gestur perempuan pada karya Kawasaki dan tubuh dan pakaian pada karya Kawasaki yang dibahas dengan menggunakan Teori Bahasa Rupa dan Studi Kebudayaan. 


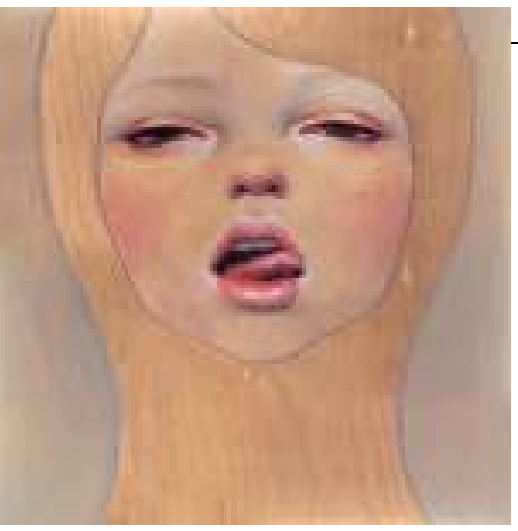

\subsection{Tubuh Perempuan dan Ekspresi Wajah Pada Lukisan Audrey Kawasaki}

Karya Kawasaki yang berjudul Lick Face merupakan satu dari banyak karyanya yang mengandung bahasa rupa NPM (Naturalis Perspektif Momenopname) khas Barat dimana adanya penekanan pada ekspresi wajah yang ditampilkan dengan ukuran pengambilan close up. Penggunaan close up ini disebabkan kerangkan berpikir seniman Barat yang menilai bahwa ekspresi wajah memegang peranan sangat penting untuk menyampaikan suatu informasi. Karya tahun 2005 ini dikerjakan pada panel kayu berukuran 15"x15" dengan menggunakan media cat minyak dan graphite.

Adaptasi ciri komik manga Jepang sebagai salah satu sumber insrirasi Kawasaki tampak terlihat jelas pada bagian wajah, dimana bagian mata digambarkan agak lebih besar, hidung digambarkan lebih mungil dari ukuran proporsional manuasia normal. Pada karya tersebut ditampilkan sebuah wajah perempuan muda bermata sayu yang pandangannya tertuju ke depan dengan mulut terbuka dan tampak sedang menjilat bagian pinggir bibirnya. Jelas bahwa ekspresi seperti ini merupakan ekspresi menggoda. Namun kontradiksi terlihat dari penggambaran wajahnya yang tampak polos tanpa riasan dan digambarkan tanpa ada elemen dekoratif di sekitarnya. Dengan demikian terlihat bahwa Audrey ingin audiens tertuju hanya pada ekspresi wajah objek.

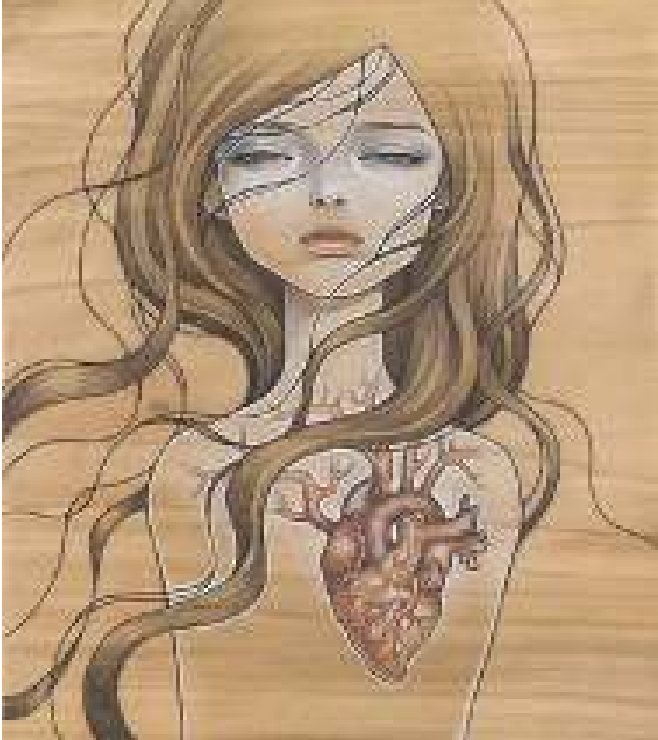

Gambar 1. Lick Face

(Sumber:

https://www.audkawa.com/2005/sjwui zz2w08s1jltak9pwc79r6di0p )

Sementara pada karya tahun 2008 yang berjudul Dishonest Heart ditampilkan sesosok perempuan berambut panjang dengan tatapan sendu ke arah depan dan mulut yang sedikit terbuka, di bagian dadanya terlihat sebuah jantung. Elemen dekoratifnya hanya terdiri dari rambut yang terurai. Berbeda dengan ekspresi pada karya pertama, pada karya ini tersirat kesan kepasrahan akan identitas seorang perempuan sebagai manusia yang secara natural terlahir memiliki hati dan perasaan. Penekanan pada karya ini terdapat pada objek jantung yang mana diasosiasikan dengan hati atau perasaan sesuai dengan judulnya,

Ciri penggambaran RWD terlihat dari cara penggambaran tembus pandang atau 'sinar $\mathrm{x}$ ' pada bagian jantung. Tampilan gaya gambar dari kedua karya tersebut, penggunaan warna yang lembut, penggunaan media kayu yang menonjolkan tekstur kayu yang hangat dan gemulai serta penggambaran wajah maupun sosok yang ramping seolah Kawasaki menyatakan kefemininan ke dalam karyanya. 


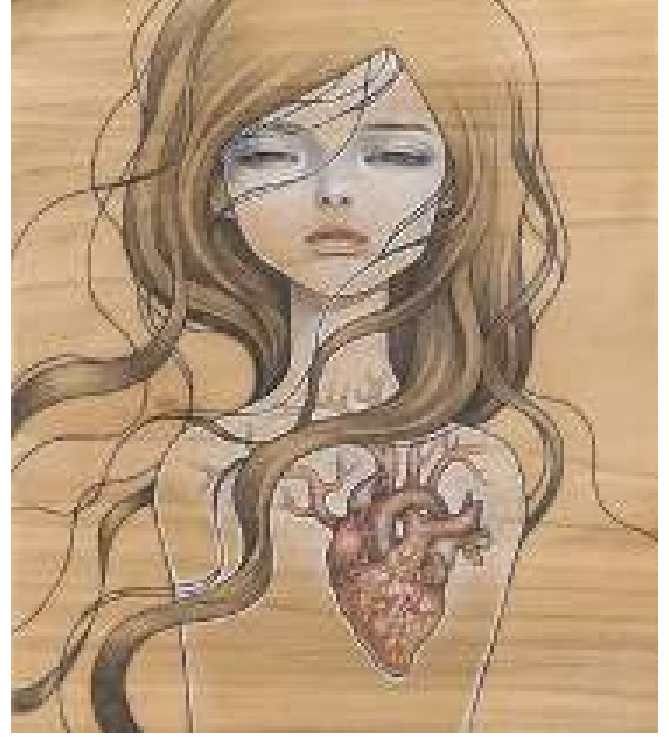

Gambar 2. Dishonest Heart

(Sumber:

https://www.audkawa.com/2008/allfpojs Itcnsimmoocqew71tozxe9)

Hal yang tampak dominan dari kedua karya ini adalah pandangan mata yang tertuju ke depan, seolah melihat langsung kepada audiens yang memandangnya. Ide tentang pandangan dapat mengacu pada pendapat Freud yang menyatakan bahwa satu-satunya sumber kesenangan seksual akan muncul ketika memandang atau dipandang dan menjadi rasa yang mendalam dan terus muncul. Kesenangan dalam memandang ini menurut versi Mulvey bisa berkembang menjadi scopofilia. Ide ini memberi acuan bukan hanya pada "mengambil orang lain sebagai objek, dan mensubjekkannya dengan tatapan yang mengontrol dan penuh rasa ingin tahu", melainkan juga "menggunakan orang lain sebagai objek stimulasi seksual melalui pandangan (Barnard, 2009: 165). Ide tentang tatapan sebagai bentuk stimulasi seksual ini banyak muncul pada karya Audrey Kawasaki. Meskipun demikian, pada beberapa karya yang lain Kawasaki menggambarkan tatapan yang menyampaikan berbagai kegelisahan, kepasrahan, ketidaktahuan dan tidak melulu mengenai "tatapan stimulai seksual".

\subsection{Gestur Tubuh Perempuan Pada Lukisan Audrey Kawasaki}

Tubuh di dalam budaya konsumen, dinyatakan sebagai sarana kenikmatan (a vehicle of pleasure). Budaya konsumen memungkinkan tanpa rasa malu memajang tubuh manusia (Barnard, 2009: vii). Pada luaran Desain Komunikasi Visual, hal ini yang sering kita konsumsi sehari-hari. Tubuh sering ditampilkan pada iklan di billboard, video klip musik, halaman muka majalah, dll. Begitu pula yang terlihat pada karya-karya Audrey Kawasaki, objek tubuh mayoritas dilukiskan tanpa busana atau dengan busana minim. Audrey dengan gamblang bereksplorasi dengan gestur yang menonjolkan lekukan-lekukan tubuh perempuan. Lekukan tubuh perempuan ini ada kalanya terlihat sensual, namun ada kalanya pula Kawasaki menonjolkan lekukan tubuh khas perempuan sebagai identitas biologis ciri perempuan yang digambarkan secara apa adanya, natural, bahkan terkesan polos. Para perempuan yang dilukiskan kesemuanya memiliki paras cantik, muda, dan berperawakan ideal. Hal ini seperti menjadi penguat akan definisi Kawasaki terhadap watak femininitas. Dalam ranah femininitas, segala sesuatu yang berkaitan dengan menciptakan dan menjaga rupa atau penampilan, merupakan hal yang mendefinisikan watak femininitas (feature of femininity) (Barnard: 2009: 166). 


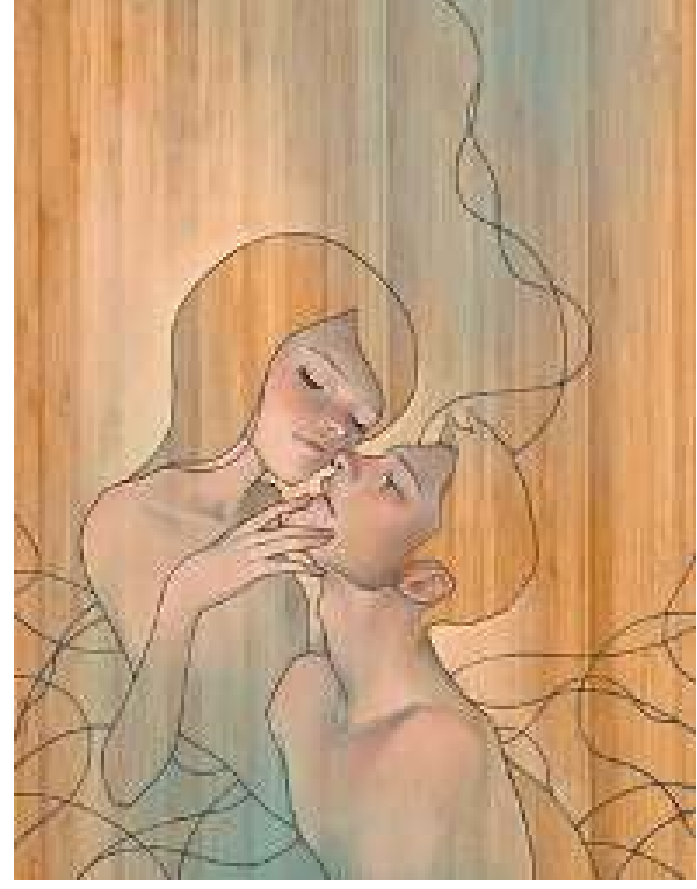

Gambar 3. To You To Me

(Sumber:

https://www.audkawa.com/2011/x6frs pyytaogr1nu9m5fkks42ipeng)

Pada beberapa karyanya, Kawasaki menggambarkan 2 figur yang saling menatap, entah antara sesama perempuan atau antara lakilaki dan perempuan. Teori psikoanalisis membahas ide tentang tatapan, khususnya tatapan laki-laki (male gaze) dan biasanya ditemui dalam hubungan dengan ide mengenai kesenangan (pleasure) dan hasrat (desire). Menurut Freud, "kesan visual tetap menjadi jalan utama yang paling sering bagi kemunculan gairah libido", menurutnya pula "kebanyakan manusia normal" memiliki hasrat untuk memandang dan memperoleh kesenangan lewat pandangan atas segala hal yang mereka jumpai yang menarik secara seksual. Kesenangan dalam memandang ini disebut scopofolia, dan dapat berkembang menjadi bentuk ekstrem atau perverse dari scopofilia yang mengacu pada voyeurism dan ekshibisionisme ( Barnard: 2009: 164).

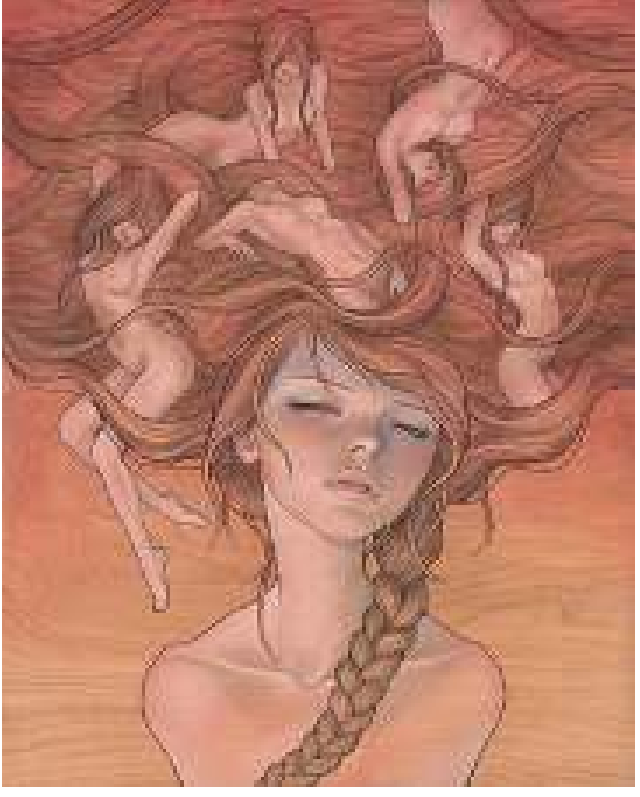

Gambar 4. She Entwined

(Sumber:

https://www.audkawa.com/2011/rnle3 g1sxu8edt0lfw8ah64hoyozqy)

Ide mengenai male gaze ini menurut Mulvey secara khusus digunakan untuk mengontrol dan memperoleh kesenangan seksual dari perempuan. Male gaze merupakan hasrat (desire) dan kesenangan (pleasure) maskulin yang dipuaskan, dan diperoleh dari tatapan. Berdasarkan pernyataan ini, perempuan hanya dianggap sebagai objek untuk dipandang. Perempuan memliki peran apa yang disebut dengan "peran ekshibisionis tradisional" untuk peran voyeuristic laki-laki (Barnard, 2009: 165). Dalam ranah ketertarikan heteroseksual, ide perempuan sebagai objek untuk dipandang ini cukup sering ditampilkan pada karya Kawasaki. Kawasaki seperti "menantang" peran voyeuristic laki-laki ketika memandang karyanya seperti yang terlihat pada karya She Entwined dan Love Songs. 


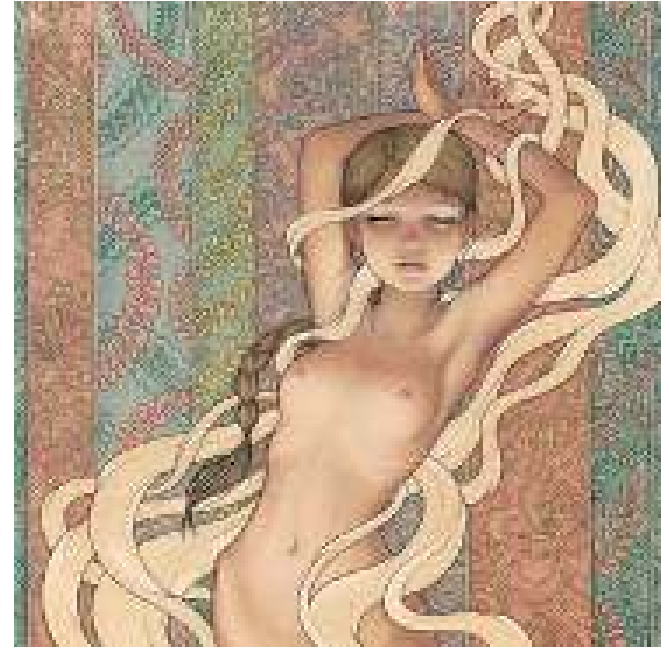

Gambar 5. Love Songs

(Sumber:

\section{https://www.audkawa.com/2011/bxjna 45h37enmlc1ylar52xvshat4q)}

Love Songs merupakan karya Kawasaki pada tahun 2011. Pada periode tahun ini elemen dekoratif yang terinspirasi oleh gaya Art Nouveau cukup kental terasa pada karya-karya Kawasaki yang dicirikan dengan penggambaran karakteristik tumbuhan yang meliuk-liuk sebagai latar belakang objek utama, sehinga secara keseluruhan karyanya terlihat menggunakan gaya eklektik.

Eklektikisme sendiri merupakan sebuah kecenderungan yang lazim digunakan pada karya sastra, seni, desain dan arsitektur, yang dicirikan dengan adanya penggabungan sebuah gaya atau kode dengan gaya dan kode-kode lain yang sama sekali berlainan karakternya. (Piliang 2003: 17)

Setelah semua ide mengenai male gaze yang sudah dibahas di atas, tidak dapat dipungkiri bahwa Kawasaki sebagai perempuan, juga mengangkat ide female gaze dimana perempuan juga menikmati pandangannya sendiri, perempuan sebagai subjek. Ide ini tampil di beberapa karyanya, contohnya pada karya Birthday Kiss. Female gaze ini juga berlaku bagi audiens perempuan yang berperan sebagai subjek ketika dihadapkan pada karyanya.

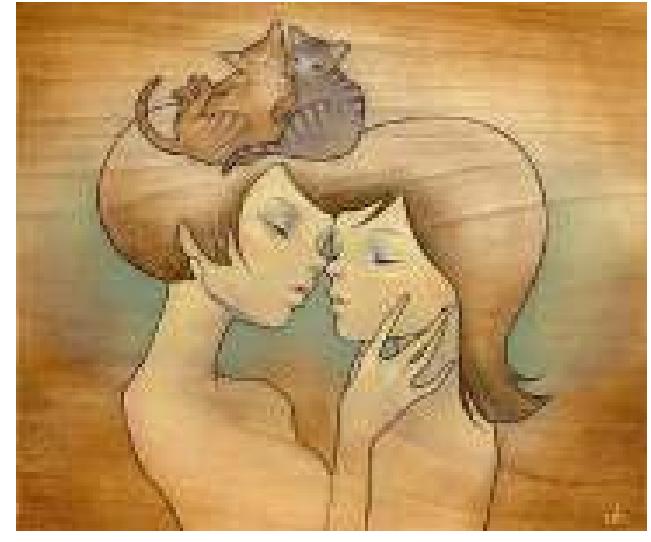

Gambar 6. Birthday Kiss

(Sumber:

https://www.audkawa.com/2006/06mx mtirna4awewr7fih77vbjkl62o)

\subsection{Tubuh Perempuan dan Pakaiannya Pada Lukisan Audrey Kawasaki}

Ide tentang tubuh di masyarakat Barat diungkapkan Foucault (1978) sebagai lokasi paling memaksa dimana tempat kekuasaan sosial diterapkan. Tubuh diyakini sebagai tempat definisi-definisi yang menyandang kekuasaan tentang normalitas sosial dan seksual. Tubuh merupakan lokasi disiplin sekaligus penghukuman bagi penyimpangan dari normanorma tersebut (Fiske, 2011: 102). Hal ini kiranya memiliki keterkaitan dengan citra perempuan di budaya Timur, dimana perempuan seringkali menerima pemaksaan di kehidupan sosialnya untuk mendapatkan pengakuan. Contohnya di masyarakat tradisional China, perempuan dituntut untuk memiliki kaki yang kecil agar dianggap cantik, padahal proses untuk mendapatkan telapak kaki yang kecil ini dapat menyakiti diri sendiri. Hal ini mirip dengan pemakaian korset di Barat, dimana perempuan dianggap cantik bila memiliki pinggang yang langsing, meskipun penggunaan korset ini membuat tidak nyaman.

Ide mengenai standar kecantikan berdasarkan bentuk anatomi tubuh tertentu yang ditunjang dengan segala atribut yang digunakan 
perempuan kiranya sejalan dengan ide Rudofsky dan Laver yang kemudian dikenal sebagai "teori pergeseran zona yang erotis". Ide ini menyatakan bahwa pakaian, dalam beberapa hal fashion, merupakan akibat dari cara memandang bagianbagian tubuh yang dianggap atraktif pada zaman yang berbeda. Ide ini didukung leh pernyataan Flugel yang mengungkapkan bahwa minat seksual budaya pada anatomi wanita terusmengalami pergeseran dari satu bagian tubuh ke bagian tubuh lain. Contohnya, pada suatu waktu pada bagian payudara, di waktu yang lain bagian belakang, lalu kaki, dan seterusnya (Barnard, 2009: 81).

Dengan demikian identitas gender perempuan dapat dikatakan dikonstruksi, ditandai, dan direproduksi melalui fashion dan pakaian (Barnard, 2009: 166). Selanjutnya pembahasan mengenai karya Kawasaki dititikberatkan pada tubuh perempuan dan pakaian serta atribut yang digunakannya. Di beberapa karya Kawasaki ini rasanya tepat bila mengangkat ide tentang pakaian wanita yang dinyatakan "diatur" oleh Prinsip Godaan. Di sepanjang sejarah dan prasejarah, pakaian wanita dimaksudkan,untuk membuat pemakainya lebih menarik bagi lawan jenisnya karena masih ada stereotype yang menyatakan bahwa pria memilih "pasangan hidup" berdasarkan daya tarik perempuan. Jadi, dapat dikatakan pakaian perempuan menunjukkan daya tarik seksualnya (Barnard, 2009: 80).

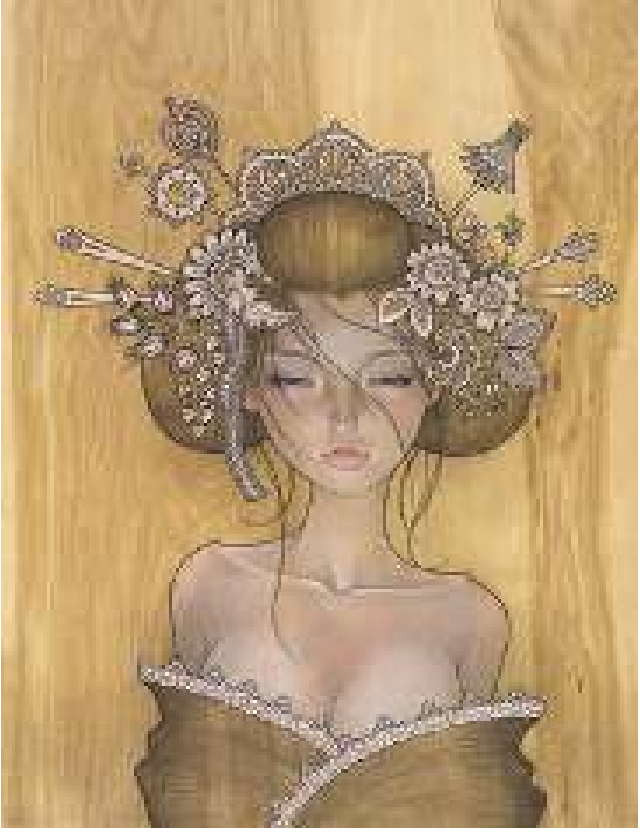

Gambar 7. Yuuwaku (Allure)

(Sumber:

https://www.audkawa.com/2011/qht53 c2z29gula8xt5tsatkn92jlq3)

Berdasarkan ide mengenai pakaian perempuan di atas maka, motivasi bagi perempuan dalam mengenakan pakaian adalah memenuhi fungsi ketidaksopanan atau ekshibisionisme. Hal ini menegaskan bahwa tugas pakaian adalah untuk menarik dan menerima perhatian pada tubuh, bukan untuk mengalihkan atau menolak perhatian tersebut (Barnard, 2009: 79). Ide mengenai pakaian untuk memenuhi fungsi ketidaksopanan terlihat contohnya pada karya Kawasaki yang berjudul Yuuwaku dan Belinda. Pada karya Yuuwaku si perempuan di posisi tengah tampak dengan rambut ditata dan memakai atribut tradisional Jepang di kepalanya. $\mathrm{Si}$ perempuan menggunakan nagajuban (baju dalam kimono) yang dilonggarkan sehingga menunjukkan lekuk leher, bahu dan dada. Di karya lain berjudul Belinda, ditampilkan seorang wanita berkostum pelayan, yang sedang berpose tidak natural. Kostumnya ketat sehingga lekukan tubuh yang ditonjolkan lebih banyak dibanding pada karya 
sebelumnya. Kedua karya ini jelas mengadaptasi ide pakaian yang memenuhi fungsi ekshibisionisme.

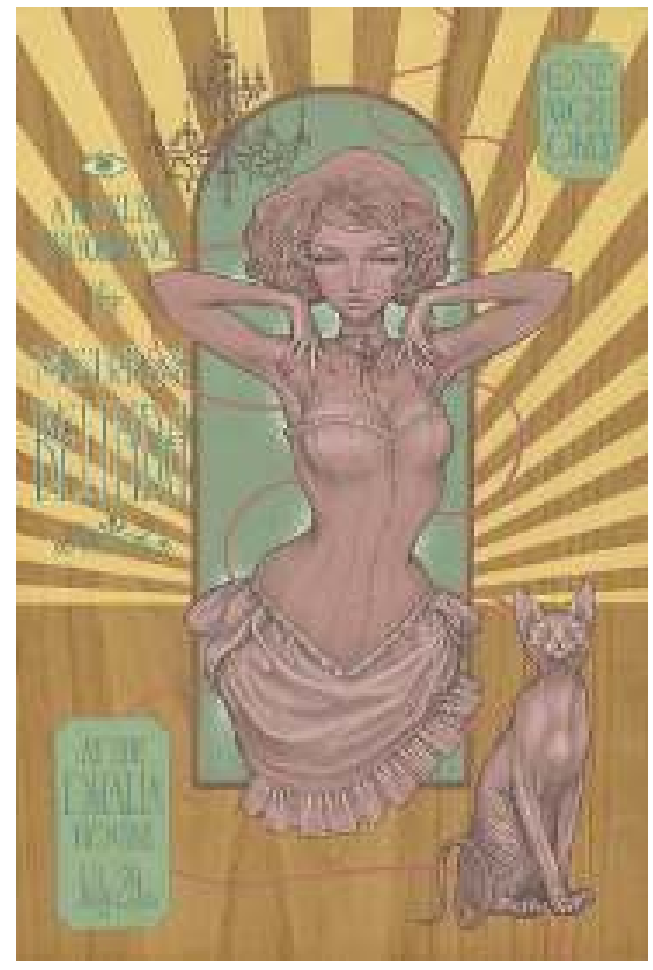

Gambar 8. Belinda

(Sumber:

https://www.audkawa.com/2017/8jzz9 31p7v4dtrj4iq44ol3sziborb)

Sebagai penetralisir dari ide sebelumnya mengenai pakaian, argumen selanjutnya menyampaikan ide sebaliknya, yaitu pakaian untuk memenuhi fungsi kesopanan. Ide ini menyatakan bahwa beberapa bagian tubuh tertentu adalah tak senonoh atau memalukan dan hendaknya ditutupi agar tidak terlihat. (Barnard, 2009: 75). Brown dalam hal ini menjelaskan mengenai pertentangan terhadap kesopanan sebagai fungsi utama pakaian: "Disini tak ada hubungan hakiki antara pakaian dan kesopanan karena setiap masyarakat memiliki konsepsinya masing-masing tentang perilaku dan pakaian yang sopan". Pernyataannya ini untuk menegaskan bahwa tak ada definisi yang benar- benar menegaskan standar kesopanan dan rasa malu yang alamiah atau hakiki, sehingga setiap budaya memiliki standar yang berbeda (Barnard, 2009: 76-77). Ide ini tampak di beberapa karya Audrey yang mengangkat identitas kebudayaan melalui atribut yang digunakan oleh perempuan di lukisannya.

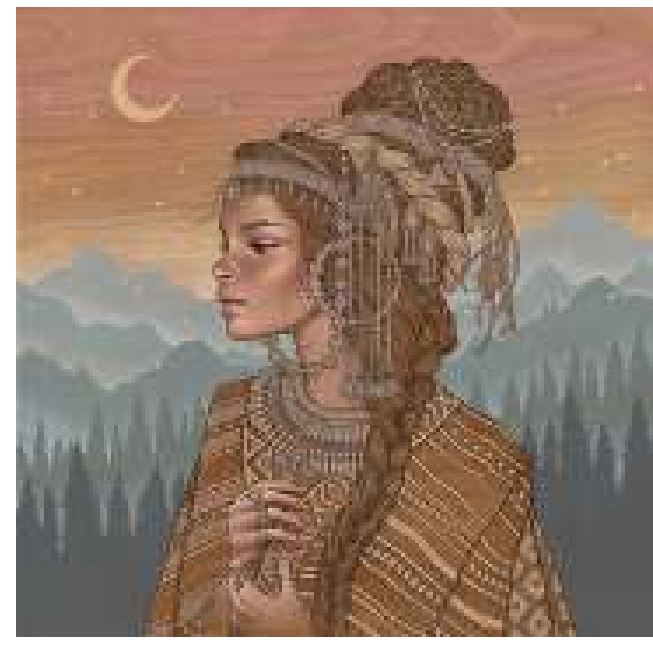

Gambar 9. Ohana

(Sumber:

\section{https://www.audkawa.com/2017/2018/ 11/13/2018/11/13/ohana)}

Ide mengenai pakaian, kesopanan dan identitas budaya tertentu terlihat pada karya Kawasaki yang berjudul Ohana dan Wurina. Pada Ohana, sepertinya Kawasaki mengangkat identitas native American yang terlihat pada pola di jubah yang dikenakan oleh objek perempuan. Lengkap dengan atribut yang cukup rumit di kepala, rambut dan leher si perempuan. Pada karya Wurina, Kawasaki mengangkat identitas Mongolia. Terlihat dari baju yang dikenakan dan atribut serta tatanan rambutnya. Dibanding karya-karya sebelumnya, 2 karya ini jauh terlihat lebih sopan, tertutup dan humanis. Keduanya jauh dari kesan sensual seperti yang digambarkan di banyak karya Kawasaki, meskipun sama-sama memandang, tapi tak ada ciri "tatapan stimulus seksual" pada kedua karya ini. Rupanya, pakaian pula dapat menjadi media konstruksi bagi pembentukan identitas perempuan. 


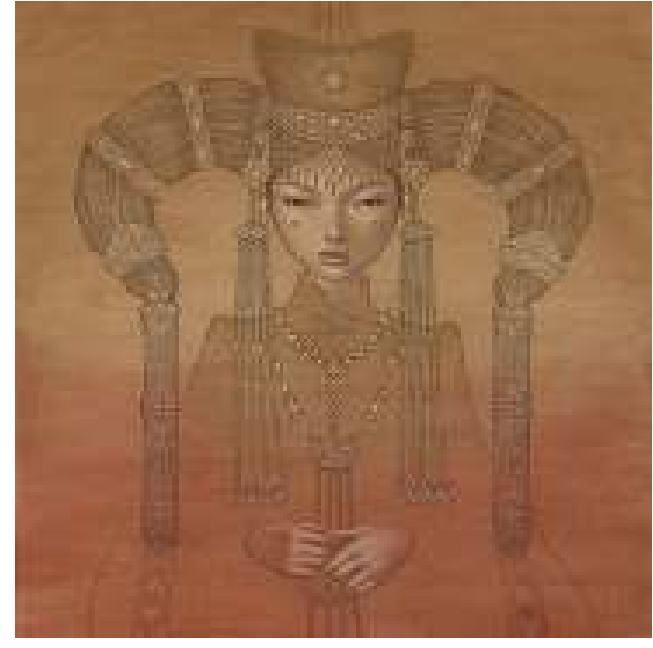

Gambar 10. Wurina

(Sumber:

https://www.audkawa.com/2017/ya6x w7vcv0p42a2hdnn73gufhsk5fo)

\section{KESIMPULAN}

Audrey Kawasaki sebagai seniman perempuan membawa permasalahan mengenai identitas, gender dan seksualitas perempuan ke dalam karya lukisannya yang mayoritas mengambil objek perempuan. Melalui gaya visual yang feminine, Audrey merayakan kebebasan perempuan akan tubuhnya sendiri, dia bebas dipandang maupun memandang baik dalam konteks tatapan pria atau bahkan tatapan perempuan sekalipun. Dia bebas memiliki ketertarikan heteroseksual atau homoseksual. Perempuan bebas menutupi tubuhnya atau membuka tubuhnya tanpa busana apapun, dan sebaliknya bebas pula menutup tubuhnya rapat-rapat. Perempuan bebas menentukan menjadi sosok inferior atau superior di dalam hubungannya dengan lakilaki. Perempuan digambarkan dapat menjadi sosok yang terbuka sekaligus misterius. Sensual dan polos di dalam waktu yang bersamaan.

\section{REFERENSI}

\subsection{Sumber Buku}

Barnard, Malcolm. 2009. Fashion Sebagai Komunikasi: Cara Mengomunikasikan Identitas Sosial, Seksual, Kelas, dan Gender. Edisi 2. Jalasutra. Yogyakarta

Fiske, John. 2011. Memahami Budaya Populer. Edisi1. Jalasutra. Yogyakarta.

Piliang, Yasraf Amir. 2003. Hipersemiotika: Tafsir Cultural Studies atas Matinya Makna. Jalasutra. Yogyakarta.

Rogers, Mary F. 2009. Barbie Culture: Ikon Budaya

Tabrani, Primadi. 2012. Bahasa Rupa. Edisi 3. Kelir. Bandung.

\subsection{Sumber Artikel Jurnal}

Lie, Firman. 2015. Tubuh dan Pakaian dalam Seni Rupa Mella Jaarsma. Jurnal Seni Rupa Galeri: Kajian Seni Rupa Modern dan Kontemporer Indonesia. 2 (1): 25-48.

Nadhiputro, Muhajir. 2012. Citra Wanita dalam Karya Seni Rupa. Urna: Jurnal Seni Rupa. 1 (1): 50-62.

\subsection{Sumber Website}

https://www.audkawa.com/bio/ diakses pada 6 Desember 2018

https://www.audkawa.com/2005/sjwuizz2w08s1j ltak9pwc79r6di0p diakses pada 6 Desember 2018

https://www.audkawa.com/2008/allfpojsltensim moocqew71tozxe9 diakses pada 6 Desember 2018

https://www.audkawa.com/2011/x6frspyytaogr1 nu9m5fkks42ipeng diakses pada 6 Desember 2018 
https://www.audkawa.com/2011/rnle3g1sxu8edt 0lfw8ah64hoyozqy diakses pada 6 Desember 2018

https://www.audkawa.com/2011/bxjna45h37enm lc1ylar52xvshat4q diakses pada 6 Desember 2018

https://www.audkawa.com/2006/06mxmtirna4a wewr7fih77vbjk162o diakses pada 6 Desember 2018

https://www.audkawa.com/2011/qht53c2z29gula 8xt5tsatkn92jlq3 diakses pada 6 Desember 2018

https://www.audkawa.com/2017/8jzz931p7v4dtr j4iq44ol3sziborb diakses pada 6 Desember 2018.

https://www.audkawa.com/2017/2018/11/13/201 8/11/13/ohana diakses pada 6 Desember 2018.

https://www.audkawa.com/2017/ya6xw7vev0p4 2a2hdnn73gufhsk5f0 diakses pada 6 Desember 2018 . 